\title{
LA VISTA AÉREA DE CÓRDOBA DIBUJADA POR ALFRED GUESDON EN 1853
}

\author{
ANTONIO GÁmiz GoRDO ${ }^{1}$ \\ Universidad de Sevilla \\ Antonio Jesús García OrTEgA ${ }^{2}$ \\ Universidad de Sevilla
}

\begin{abstract}
Las vistas aéreas de Alfred Guesdon constituyen un motivo de recurrente interés por su gran belleza y fiel reflejo de importantes ciudades de la época, así como por los interrogantes que plantea su elaboración. Tras reseñar algunas vistas aéreas dibujadas a mediados del XIX, se revisan las hipótesis sin documentar sobre la relación de Clifford con las vistas españolas de Guesdon y sobre la problemática de su construcción gráfica con la ayuda de planos, fotografías o globos aerostáticos. Sobre ello arroja luz el análisis del inédito dibujo de Córdoba (1853), cuya precisión se constata al compararlo con el coetáneo plano de Montis (1851). En un recorrido por la ciudad dibujada y sus principales hitos se corrobora el valor documental de esta imagen de Guesdon, que supo integrar el dibujo tradicional con los avances técnicos del momento.
\end{abstract}

Palabras clave: Guesdon; Córdoba; dibujo; fotografía; globo; ciudad; vista; siglo XIX.

\section{THE AERIAL VIEW OF CORDOBA DRAWN BY ALFRED GUESDON IN 1853}

The aerial views by Alfred Guesdon are considered works of special interest due to their quality and beauty. These drawings are a faithful portrait of the great cities of the period, and a mystery in terms of their creation. After reviewing some of the aerial drawings of the mid- $19^{\text {th }}$ century, the author considers undocumented hypotheses regarding the relationship of Charles Clifford to the drawings by Guesdon of Spanish cities, and the issues related to their elaboration by means of plans, photographs and hot-air balloons. Some light is shed on this matter thanks to the unpublished drawing of the city of Cordoba (1853), whose accuracy is evident when compared to a city plan drawn by Montis (1851). A journey through the city of Cordoba and its landmarks proves the documentary value of the drawing by Guesdon, who knew how to combine traditional drawing skills with the latest technical advances of his time.

Key words: Guesdon; Cordoba; drawing; photograph; hot-air balloon; city; view; $19^{\text {th }}$ century.

Como citar este artículo / Citation: Gámiz Gordo, Antonio/ García Ortega, Antonio Jesús (2018): "La vista aérea de Córdoba dibujada por Alfred Guesdon en 1853". En: Archivo Español de Arte, vol. 91, núm. 361, Madrid, pp. 29-45. https://doi.org/10.3989/aearte.2018.03

Alfred Guesdon revolucionó las formas de ver y mostrar la ciudad vigentes a mediados del siglo XIX. Sus vistas son fieles testimonios gráficos de gran valor documental para investigar el paisaje urbano y sus transformaciones históricas. Desde novedosos puntos de vista y con los avances técnicos entonces disponibles publicó bellas perspectivas aéreas de más de cien ciudades

\footnotetext{
1 antoniogg@us.es / ORCID iD: http://orcid.org/0000-0001-6188-3167.

2 agarciall@.us.es / ORCID iD: http://orcid.org/0000-0001-5907-5283.
} 


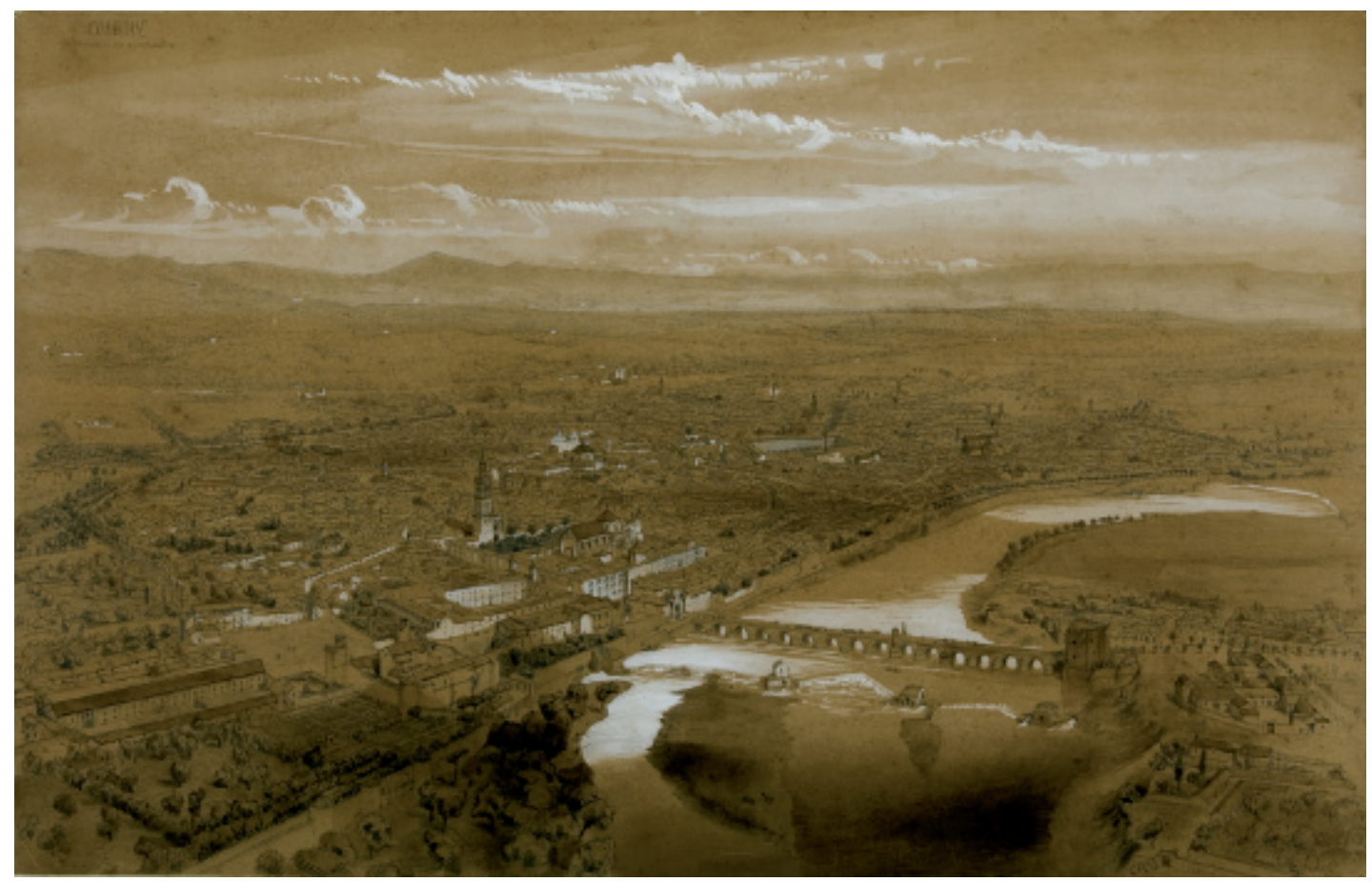

Fig. 1. Alfred Guesdon: Vista aérea de Córdoba [dibujo a lápiz y aguada sobre papel], Museo de Bellas Artes de Nantes [inv1533], 1853.

en las que se muestra un patrimonio enriquecido durante siglos, y en parte perdido o transformado con la llegada del progreso o la modernidad. Aunque las litografías de Guesdon resultan bastante conocidas, en general han sido poco estudiadas y hasta ahora no se había analizado ninguno de sus dibujos originales. Este trabajo se centra en el original inédito de Córdoba (fig. 1), conservado en el Museo de Bellas Artes de Nantes, acometiendo una amplia revisión de su contexto y un detallado estudio de la ciudad representada, entre otras cuestiones tratadas a continuación.

\section{Vistas aéreas de ciudades a mediados del XIX}

A partir del siglo XVI se despertó en Europa un gran interés por conocer ciudades del mundo a través de imágenes que mostraban sus perfiles y rasgos más destacados. Desde entonces proliferó la edición de vistas urbanas con diversos grados de fiabilidad documental, según los intereses o habilidades de cada dibujante o grabador. La llegada de la fotografía hacia 1840 provocó importantes cambios en las formas de obtener dichas imágenes. Los reportajes fotográficos vendrían a sustituir a los cuadernos de viaje y a las perspectivas urbanas acometidas según la tradición vedutista.

Un avance técnico de finales del siglo XVIII, la posibilidad de volar en globo aerostático, proporcionaría novedosos puntos de observación a vista de pájaro. Hacia 1830-40 se acometieron destacadas imágenes aéreas de ciudades, como por ejemplo, Aeronautical view of London, dibujada por R. Havell en 1831, o Panorama of London as seen from the basket of a balloon, publicada por Le Roi en 1836, entre otras. Una vez que la técnica del daguerrotipo se hizo pública en Francia, en 1839, el interés por la fotografía se propagó rápidamente entre buscadores de nuevos negocios, según ilustra una litografía de Théodore Maurisset publicada en 1840 con el título Daguerrotipomanía (fig. 2). En ella se recrean variadas formas con las que se esperaba sacar 


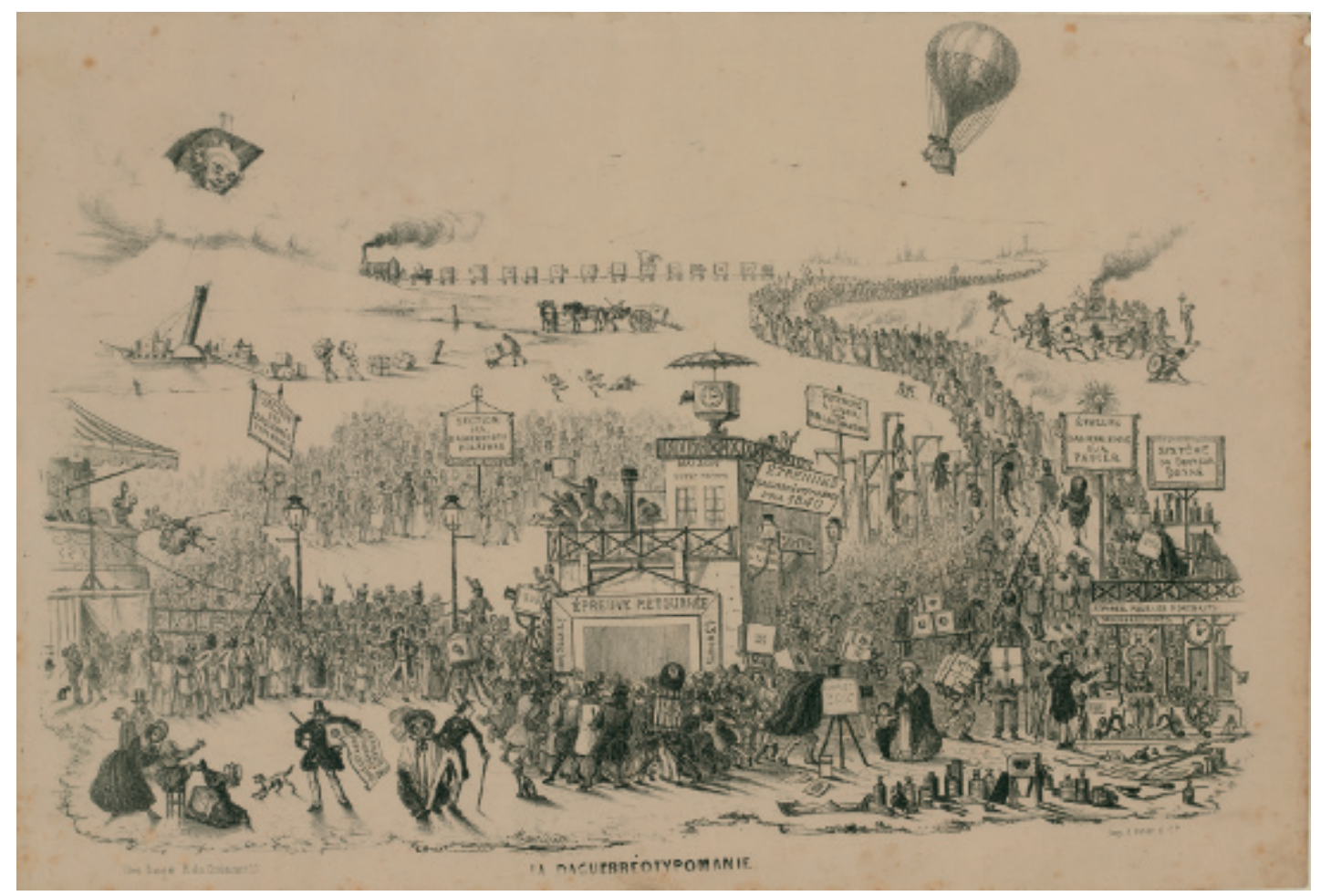

Fig. 2. Théodore Maurisset: La Daguerreotypomanie [litografía], 1840.

provecho a esta nueva técnica y aparece un daguerrotipo volando en la canasta de un globo aerostático (fig. 3).

Como importante antecedente de la vista de Córdoba deben mencionarse las litografías de Jules Arnout tomadas en globo del natural: Excursions Aeriennes, prisses en ballon d'apress nature et lithographiées ${ }^{3}$ impresas en París, y publicadas hacia 1846-48 en París y Londres, con 16 vistas aéreas de ciudades francesas más 6 inglesas en las que se dibujan globos aerostáticos. Esta obra mantuvo una clara continuidad con las colecciones de láminas sobre ciudades europeas a vista de pájaro, impresas en París por Hauser y Delarue, de Alfred Guesdon (1808-1876), pintor, litógrafo y arquitecto nacido en la ciudad de Nantes y autor del dibujo de Córdoba aquí presentado. Hacia 1848 se publicó L'France a vol d'odiseau, con 44 dibujos de 37 ciudades $^{4}$ de dicho autor. Y hacia 1848 se dibujaron otras 45 láminas de Guesdon incluidas en L'Italie a vol d'odiseau, publicadas como fascículos

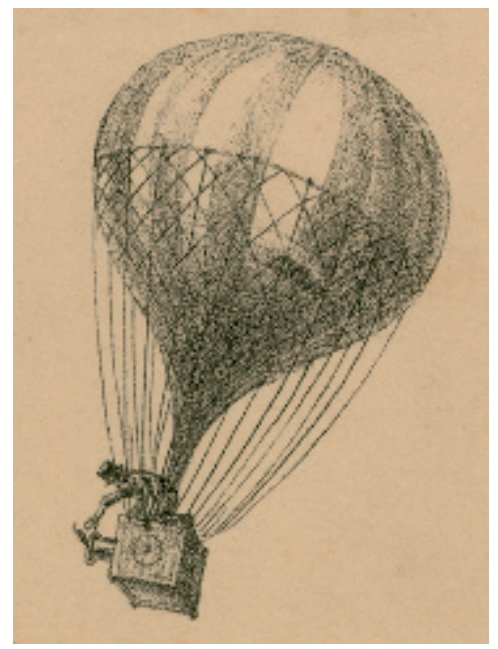

Fig. 3. Théodore Maurisset: La Daguerreotypomanie [litografía, detalle],1840.

\footnotetext{
${ }^{3}$ Incluye vistas de París, Versalles, Saint Cloud, Orleans, Fontainebleau, Rouen, Le Havre, Nantes, Blois, Dieppe, Tours, Angers, Epsom, Brighton, Windsor, Greenwich y Londres.

${ }^{4}$ Incluye vistas de Nantes, Angers, Tours, Blois, Nevers, Lyon, Grenoble, Saint-Ettienne, Valence, Avignon, Arles, Toulon, Digne, Gap, Boorg-en-Bresse, Besançon, Dijon, Màcon, Auxerre, Lonsle-Saulier, Strasbourg, Metz, Nancy, Chartres, le Havre, Brest, Saint-Malo, Saint-Lô, Cherbourg, Rennes, Laval, Bordeaux, Toulouse, Carcassonue, Montpellier, Nimes, Marseille, Lyon, Brest, Bordeaux, Toulouse, Toule (2) y Marseille (3).
} 


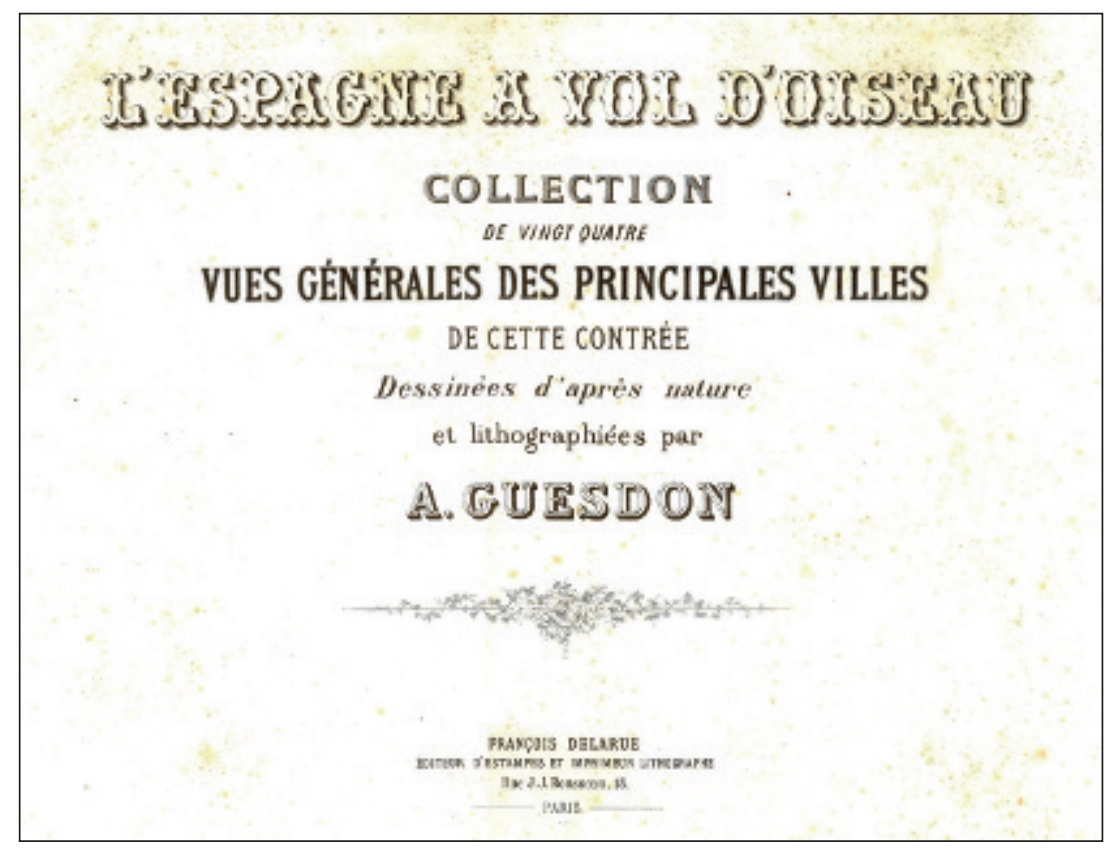

Fig. 4. Alfred Guesdon: L'Espagne a vol d'odiseau [portada] h. 1853-56.

a partir de $1849^{5}$. Jules Arnout participó como litógrafo en ambas colecciones. Además existe una serie de vistas aéreas de Guesdon sobre ciudades de Suiza ${ }^{6}$ publicadas hacia 1858, más otras vistas sueltas sobre Bruselas y sobre Sebastopol.

En la colección sobre España, Guesdon dibujó y litografió 24 láminas bajo el título L'Espagne a vol d'odiseau (fig. 4), con tamaño de $285 \times 440 \mathrm{~mm}$., incluyendo 16 ciudades o lugares notables $^{7}$. Sólo se conocen 4 dibujos originales preparatorios de dichas vistas: sobre Burgos y Córdoba conservados en el Museo de Nantes, sobre Cádiz, en el Institut Cartogràfic de Catalunya, y sobre Valencia, subastado en Sotheby's (18-5-1993). Y sólo algunas vistas incluyen la fecha, como el original de Burgos (1852), los de Córdoba, Cádiz y Valencia (1853), una litografía de Madrid (1854) u otra de Barcelona (1856). Además Guesdon publicó en L'Illustration, Journal Universal dibujos sobre Toledo (16-7-1853), Jerez (10-12-1853) y Gibraltar (28-10-1854), entre otros.

En el catálogo de fondos del editor François Delarue ${ }^{8}$ de 1858 hay un amplio apartado dedicado a panoramas y vistas de ciudades "pour servir pour Optiques et Cosmoramas", o sea, para visualizar con artilugios ópticos de la época, numeradas desde el 1717 al 2425 . Entre ellas se citan vistas "à vol d'odiseau" debidas a destacados dibujantes o litógrafos: Venecia (n. ${ }^{\circ} 1776$, Rouargue), Nueva York (n. ${ }^{\circ}$ 1801, Asselineau), además de las ya citadas Excursions Aeriennes, prisses en ballon d'apress nature... (n. ${ }^{\circ} 1994$ al 2015); todas ellas previas a las vistas españolas de Guesdon (n. 2068 al 2061).

En la década de 1850 cabe destacar otras vistas aéreas cuyo título hace referencia al globo aerostático, como View of London from the north as seen from a balloon de John Henry Banks

\footnotetext{
${ }^{5}$ Incluye vistas de Torino (2), Alessandría, Génova (2), Nizza, Milano (2), Cremona, Coma, Mantova, Parma, Piacenza, Modena, Venezia (2), Padova, Verona, Vicenza, Brescia, Bergamo, Trieste (2), Firenze (2), Pisa, Livorno (2), Siena, Lucca, Roma (3), Ancona, Perugia, Bologna (2), Ferrara, Napoli (2), Pompei, Palermo, Messina (2), Catania.

${ }^{6}$ Incluye vistas de Fribourg, Sion, Berne, Vevey, Ginebra (2), Lausanne y Berna,

7 Incluye vistas de Alicante, Barcelona (2), Burgos, Cádiz (2), Córdoba, Málaga, Gibraltar (3), Granada (2), Jerez, Madrid (2), San Lorenzo del Escorial, Segovia, Sevilla (2), Toledo, Valencia (2) y Valladolid. Además hay una vista similar de San Sebastian desde el mar, dibujada por R. Bouquet y litografiada por Guesdon.

${ }^{8}$ Delarue, 1858.
} 
(1851); o el bello óleo Vue generale de Paris prise le l'Observatoire, en ballon de Victor Navlet (1855) que mide unos $7 \times 4$ metros, conservado en el Museo de Orsay de París. Además deben mencionarse las vistas del Voyage aérien en Europe. Collections de vues à vol d'oiseau de tuotes les capitales, chefs-lieux et villes importantes de chaque pays estampado por el editor Arthur Hauser hacia 1854.

Según John W. Reps ${ }^{9}$ en el siglo XIX hubo en Norteamérica más de dos mil ciudades dibujadas a vista de pájaro, una producción sin paralelismo en el mundo. Sin embargo, casi todas ellas parecen tener una calidad técnica inferior a las Guesdon, aunque hay algunas muy bellas datadas hacia 1850-1860 (Boston, Baltimore, Nueva York...) que hacen pensar en su elaboración con medios bastante avanzados.

Por último, cabe citar un libro publicado en París (1855) Exposition universelle de 1855. Une dernière anexe au Palais de l'Industrie, cuyo autor, M. Andraud, hablaba en su capítulo undécimo sobre topografía y elaboración de mapas posicionando el daguerrotipo desde un globo cautivo de forma perpendicular al suelo. La elaboración de fotografías aéreas se concretó en la patente del 23 de octubre de 1858 del dibujante y caricaturista francés Félix Tournachon, conocido como Nadar, considerado como pionero en la fotografía aérea, tras usar la canasta de su globo aerostático como laboratorio para trabajar con la técnica del colodión húmedo.

\section{Sobre la hipotética colaboración del aeronauta y fotógrafo Charles Clifford}

Se han formulado hipótesis, revisadas a continuación, sobre la posible colaboración del fotógrafo Charles Clifford en las vistas españolas de Guesdon ${ }^{10}$. La labor en España de Clifford, fotógrafo oficial de Isabel II, ha sido objeto de importantes estudios ${ }^{11}$, que, sin embargo, facilitan escasos datos previos a su llegada a Madrid en 1850. Clifford usaría los últimos adelantos en el arte del daguerrotipo, y en sus comunicaciones con la Corona firmaba hasta 1851 como "Aereonaut Anglais". En un texto de Gerardo Kurtz ${ }^{12}$ se detalla su actividad como aeronauta que elevó su globo sobre la Plaza de Toros de Madrid en enero de 1851, en una singular "corrida con ascención aerostática". En los carteles del espectáculo aparecían los nombres de "C. Clifford y A. Goulston". Algunos autores han supuesto que Goulston podía corresponder con la palabra Guesdon, escrita erróneamente ${ }^{13}$, pero hoy se sabe que éste era un empresario dedicado a los globos, con el que Clifford ya había compartido una ascención en Burdeos, según la prensa de 19 de septiembre de 1850 (The London Evening Standard). Goulston falleció en Manchester en junio de 1852 en un accidente de globo, según detalla un reciente artículo que documenta los espectáculos de entonces con globos y caballos ${ }^{14}$.

En la prensa del 14 de noviembre de 1850 (El Clamor Público) se destacaba la avanzada capacidad técnica de Clifford, que tenía previsto obtener vistas de Madrid desde el globo: "Daguerrotipo veloz. No podemos por menos de recomendar al público el nuevo método de retratar al daguerrotipo, invención de los célebres aeronautas Mr. Clifford y Goulston, no sólo por su exactitud y perfección, sino por la sorprendente prontitud con que se hacen (...) Parece que si consiguen verificar las ascensiones que tienen proyectadas, piensan reproducir el panorama de Madrid a vista de pájaro".

El 17 de enero de 1851 Clifford comentaba en prensa (La Patria) su reciente ascensión desde la plaza de Toros: "Mucho sentimos no haber podido tomar con el daguerrotipo la vista de Madrid, pero confiamos en que en otra ocasión lograremos sacar un paisage tan nuevo como exacto". El 21 de enero de 1851 se anunciaba (La España) una segunda ascención de Clifford y

\footnotetext{
9 Reps, 1984; 1998.

10 Gámiz, 2004.

11 Fontanella, 1999.

12 Kurtz, 1997.

13 Quirós, 1991: 148.

14 Bullough, 2015: 129-137.
} 
Goulston. Curiosamente en una de las vistas de Guesdon sobre Madrid la plaza de Toros aparece en primer plano, aunque no se dispone de datos sobre la posible colaboración de Clifford.

Por otra parte, en prensa de 27 de febrero de 1851 (El Clamor Público) se anunciaban 12 láminas 15 "representadas de una manera tan nueva como exacta", bajo el título España Panorámica, la primera sobre Madrid "figurando ser tomada desde un globo sobre su centro". Su punto de vista se eleva sobre la puerta del Sol, e incluye un globo aerostático, pero su calidad gráfica es muy inferior a las de Guesdon. Fue dibujada y litografiada por Eduardo de León y Rico, que en 1846 había publicado un manual titulado El daguerrotipo. Manual para aprender por si solo tan precioso arte y manejar los aparatos necesarios. Ello hace pensar en otros daguerrotipistas ${ }^{16}$, e incluso en el propio Guesdon como fotógrafo.

Aunque Clifford contaba hacia 1856 con más de 400 vistas de España, y fotografió todas las ciudades dibujadas por Guesdon, salvo Valencia, no se conoce ninguna foto suya tomada desde globo; sólo cabe mencionar una vista de Granada idéntica, aunque con menor tamaño, a la de Guesdon, publicada en 1860 por el Reverendo Richards Roberts en An autumn tour in Spain in the year 1859. En las primeras páginas de dicho libro figura el agradecimiento a Clifford por permitirle usar sus fotografías para ilustrar el libro. Y en el caso de Toledo cabe destacar la cercanía y parecido entre una foto de Clifford y la vista de Guesdon ${ }^{17}$.

Podría pensarse que las fotos aéreas de Clifford no se han llegado a conocer debido a la supuesta actividad de éste como espía, dado el indudable interés militar de estos documentos gráficos; no debe olvidarse que en 1849 tuvo lugar el primer intento de bombardeo aéreo de la historia, con globos aerostáticos, de Austria contra la sublevada Venecia. Pero sobre todo deben considerarse las dificultades técnicas que implicaría la ejecución de fotografías desde un globo en aquellos años. En todo caso, la colaboración entre Guesdon y Clifford en las vistas españolas sigue siendo una hipótesis sin confirmar de forma documental.

\section{Unas vistas demasiado perfectas. Interrogantes sobre su elaboración}

Las vistas de Guesdon resultan de gran interés porque documentan con precisión más de un centenar de ciudades a mediados del XIX, antes de importantes transformaciones urbanas, así como por los interrogantes que plantea su proceso de elaboración. A la vista de su minuciosidad y realismo, son cuestionables las palabras "desinees d'apres nature" que figuran en la portada de la publicación (fig. 5), pues es casi imposible que unos dibujos tan detallados y precisos pudiesen acometerse del natural, desde un globo aerostático que se movía. Dichas palabras aparecen también en conocidas vistas publicadas hacia 1840-1850 que usaron daguerrotipos, como las de Chapuy, Girault de Prangey o Parcerisa, y parecen responder a una estrategia comercial que trataba de subrayar que eran originales, y no plagios, bastante frecuentes por entonces.

En la nota necrológica sobre Guesdon que en 1876 publicó su amigo Charles Marjonneau se decía que los dibujos se realizaban en el tablero a partir de un plano, no del natural, contradiciendo la portada de la publicación: "Con la ayuda de un plano geométrico de rigurosa exactitud, y que transformaba en perspectiva elevando mucho la línea de horizonte, el artista llegaba a trazar, en este tablero tan bien preparado, la elevación de las casas y de los monumentos de la ciudad, suponiendo que se encontraba en un globo, o en un punto muy elevado..."18

En este sentido se ha afirmado que para un dibujante experto como Guesdon, que cuenta con una buena planta de la ciudad, no sería necesaria la ascensión ${ }^{19}$. Así, destacados autores ${ }^{20}$ descartan el posible uso de primitivas fotografías y postulan el uso de la cartografía urbana del

\footnotetext{
15 Madrid, Aranjuez, La Granja, Barcelona, Burgos, Toledo, Sevilla, Granada, Valencia, Bilbao y Cartagena.

16 Torrella / García / Martí / Ferrer, 2014.

17 Porres / Cerro / Isabel, 1991: 13 y 21. Fontanella, 1999: 108-109.

18 Marjonneau, 1876: 485-491.

19 Benet, 1983: 9-13 y 31.

20 Stroffolino, 2012. Besse, 2013: 66-82. Pérez, 2015: 252-253
} 
momento. Incluso se ha dicho que "las perspectivas están elaboradas a partir de una serie de levantamientos parciales efectuados desde distintos puntos altos"21, suponiendo un método similar a los usados en el Renacimiento.

También se ha dicho que por entonces era imposible tomar fotografías en vuelo y obviamente realizar dibujos tan precisos y detallados desde un globo: "hay quién todavía defiende que las vistas aéreas del siglo XIX se realizaron con ayuda de la fotografía y el vuelo en globo. Esto es obviamente imposible. No es fácil dibujar desde un globo: como mucho se pueden realizar algunos esbozos incompletos [...]. El apoyo de la fotografía, que resolvería la dificultad de dibujar, no sería posible hasta un tiempo después"22.

Además deben considerarse otros importantes argumentos que desconfían del posible uso de globos:

\footnotetext{
"existen otras causas, de diferente naturaleza, que nos llevan a negar la existencia de esas supuestas ascensiones en globo de Guesdon en 1853: el transporte del globo de ciudad en ciudad, en una España sin ferrocarriles, tendría que hacerse en barcos o en carros; no había fábricas de gas en muchas ciudades españolas y, finalmente (tratándose de acontecimientos de extraordinaria e ineludible notoriedad pública) no existe referencia alguna en la prensa de las ciudades represen$\operatorname{tadas}^{23} "$.
}

En relación a toda esta problemática debe destacarse que en los dibujos originales de Guesdon consultados (Burgos, Cádiz y Córdoba) no se han apreciado las líneas auxiliares imprescindibles para construir una perspectiva cónica sobre el tablero de dibujo. En todo caso, resulta imposible que las vistas de Guesdon se elaborasen sólo a partir de una planta de la ciudad, por una sencilla y evidente razón: este tipo de representación bidimensional no incluye los incontables datos sobre alzados de edificios, cubiertas, patios interiores, jardines, y otros muchos detalles tridimensionales dibujados por Guesdon. Se necesitarían dibujos auxiliares, o los recursos fotográficos habituales en las editoriales de París ya citadas, para obtener dichos datos.

Por otro lado, una metodología basada exclusiva o principalmente en la toma de dibujos auxiliares in situ, parece a priori poco viable para la gran empresa gráfica que abordó Guesdon. Según ilustra el caso de la maqueta de Cádiz, realizada entre 1777 y 1779 por encargo de Carlos III, se requirió un preciso plano de planta, más planos de fachadas y cubiertas de cada edificio, en una compleja tarea de toma de mediciones acometida por al menos 5 personas durante cerca de 24 meses, con los más avanzados medios técnicos de entonces, como cámara oscura, y contando con planos de la ciudad existentes ${ }^{24}$. No resulta creíble que Guesdon elaborase de este modo sus más de 100 vistas urbanas en tan corto tiempo, pues hubiese requerido un despliegue de medios inviable por el coste y tiempo necesario. Debió de usar artilugios ópticos o primitivas fotos para obtener los precisos datos necesarios para la construcción gráfica de cada vista ${ }^{25}$.

El análisis comparado entre las vistas de Guesdon y planos de su época podrá aportar, en futuros estudios, nuevos datos sobre su enigmático proceso de elaboración. Si los planos de entonces tienen importantes errores o deformaciones que Guesdon corrigió, como ocurre en el caso de Jerez, una perspectiva cónica tan exacta solo pudo construirse a partir de fotografías, salvo que Guesdon elaborase nuevos planos de cada ciudad, algo muy improbable y que a priori quedaría lejos de sus intereses.

21 Lleó, 1986

22 García, 1994: 22. Otros reconocidos autores apuntan en este mismo sentido: Rodríguez, 2015: 17-18. Pérez, 2015: 252-253.

23 Garófano, 2014. Entre 1847 y 1855 los globos aerostáticos se convirtieron en Barcelona en un entretenimiento bastante popular, según noticias de la prensa de la época. Rius, 2012.

${ }^{24}$ Granado, 2012: 150-154. Granado / Martín, 2016: 268-281.

25 Sobre la dificultad de acometer estos dibujos véase Pardo, 1995: 393-396. También cabe pensar en el posible uso de fotos de maquetas urbanas existentes de algunas ciudades, como la citada de Cádiz, o las de León Gil de Palacio sobre Valladolid y Madrid hacia 1828. 

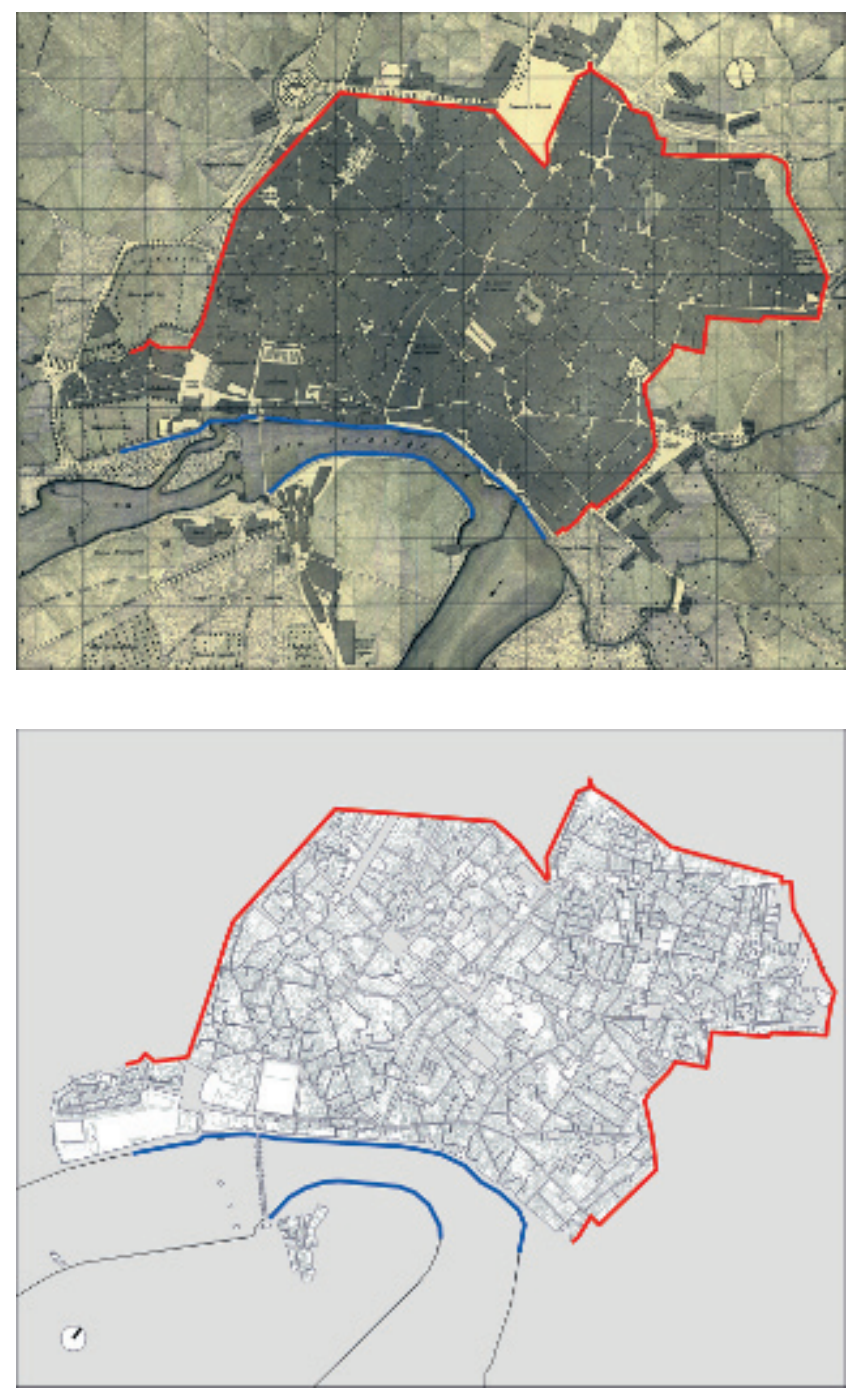

Fig. 5, 6, 7. Francisco J. Orellana García: Muralla (línea roja) y borde del río (línea azul), 2016:

- sobre el plano de Córdoba de Montis (1851).

- sobre plano actual de Córdoba. - sobre la vista aérea de Córdoba de Guesdon (1853).

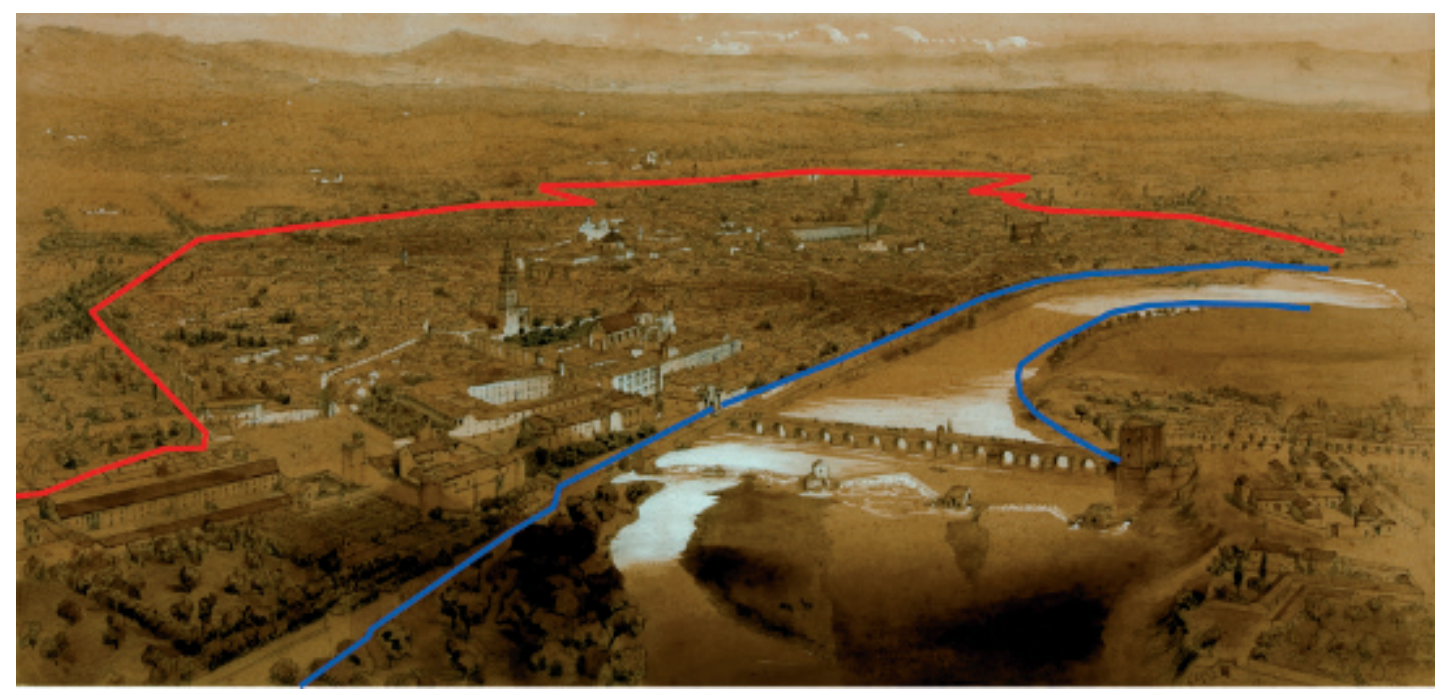

Archivo Español de Arte, vol. XCI, n. ${ }^{\circ}$ 361, pp. 29-45, enero-marzo 2018 ISSN: 0004-0428, eISSN: 1988-8511, https://doi.org/10.3989/aearte.2018.03 
En el caso de Córdoba aquí estudiado se han comparado el dibujo original de Guesdon y el plano de la ciudad de Montis de 1851. En éste último se han remarcado con línea gruesa la muralla (rojo) y el borde del río (azul) (fig. 5) y se han superpuesto a un fidedigno plano actual (fig. 6) constatándose la precisión del plano de Montis. A continuación, mediante un programa informático de Autocad en tres dimensiones, se han puesto en perspectiva cónica las citadas líneas azul y roja, superponiéndolas también al dibujo de Guesdon. Su coincidencia con la muralla y el borde del río (fig. 7) demuestra la gran precisión métrica de la vista de Guesdon y que el sistema de representación usado responde a una cónica y no a otro tipo de perspectiva ${ }^{26}$. Ésta se realizó con un punto de vista situado a unos doscientos metros de altura, según los cálculos del programa informático usado.

Dado que los fundamentos de la perspectiva cónica y de la fotografía como sistema de representación son idénticos, el encaje previo de Guesdon solo pudo obtenerse a partir del plano de Montis en un tablero de dibujo, o a partir de fotografías desde globo, posiblemente más de una. Pero en todo caso tuvo que completarse con muchos datos que no ofrece el plano, aportados por imágenes auxiliares, con detalles solo visibles desde un globo. Ello se constata en el análisis de la vista de Córdoba desarrollado a continuación.

\section{El dibujo y la litografía de Guesdon. Antecedentes gráficos}

El dibujo original de Guesdon está fechado y firmado por el propio autor, en el lienzo sur del Alcázar, con el rótulo "A. Guesdon 1853". Dicha fecha, que no se transcribió a la litografía, despeja dudas sobre la datación de esta vista cordobesa ${ }^{27}$. También incluye un título en el ángulo superior derecho: "CORDOUE. VUE D'AU-DESSUS DU GUADALQUIVIR" (Córdoba. Vista desde encima del Guadalquivir). Está realizado a "Lápiz, sepia y aguada sobre papel preparados", según la propia ficha del museo de Bellas Artes de Nantes, y con lápiz blanco se resaltan algunos edificios o elementos que dan gran viveza a la composición.

La posterior litografía, de la que existen ejemplares con un bello coloreado de la época (fig. 8), resultaría prácticamente coincidente con el dibujo original, salvo leves diferencias. Algunos detalles se modificaron al estamparse: en la iglesia de San Pedro se cambió el número de huecos de la nave central y la torre de la iglesia de La Magdalena se remató con una cúpula, en vez de sus cuerpos prismáticos superpuestos, como insinúa confusamente el dibujo previo. También muchas iglesias, como Santa Marina, resultan más esbeltas en la litografía que en el dibujo, reforzándose así su carácter de hitos urbanos.

En todo caso, cabe destacar una gran diferencia respecto a otras vistas precedentes de la ciudad de Córdoba, tanto al mostrar una amplia visión urbana, como en su mayor precisión y deta1le. Así, en las vistas de Wyngaerde (1567) o Baldi (1668) el punto de observación se situó al nivel del río, mientras que otras presentan un acusado nivel de simplificación, como ocurre en el dibujo de la colección Vázquez Venegas $(1752)^{28}$, o en la vista del "Civitates Orbis Terrarum" (1617). No obstante, todas ellas, y otras visiones de artistas y viajeros del XIX que pasaron por Córdoba (Laborde, Roberts, Ford, Vivian, Chapuy, Taylor, Parcerisa...) resultan de gran valor para cotejar el estado de muchos elementos urbanos. En este sentido también cabe mencionar el interés de algunos planos parciales de la muralla o sus puertas, localizados en el Archivo Histórico Municipal de Córdoba, realizados con motivo de reformas puntuales, realineaciones, concesiones de terreno público, conflictos de titularidad, etc.

No se sabe si Guesdon pudo conocer dicho corpus gráfico, que le resultaría en gran parte inaccesible, aunque es probable que conociese dos planos generales de la ciudad entonces existentes. El primero, llamado plano de Karwinski o "de los Franceses", data de 1811 y su original

\footnotetext{
${ }^{26}$ Se descartan las hipótesis de de que fuera una perspectiva caballera o militar, según Cosano, 1999: 68.

27 Se había fechado en 1859, según Cosano, 1999: 68.

28 García Ortega / Gámiz Gordo, 2010.
} 


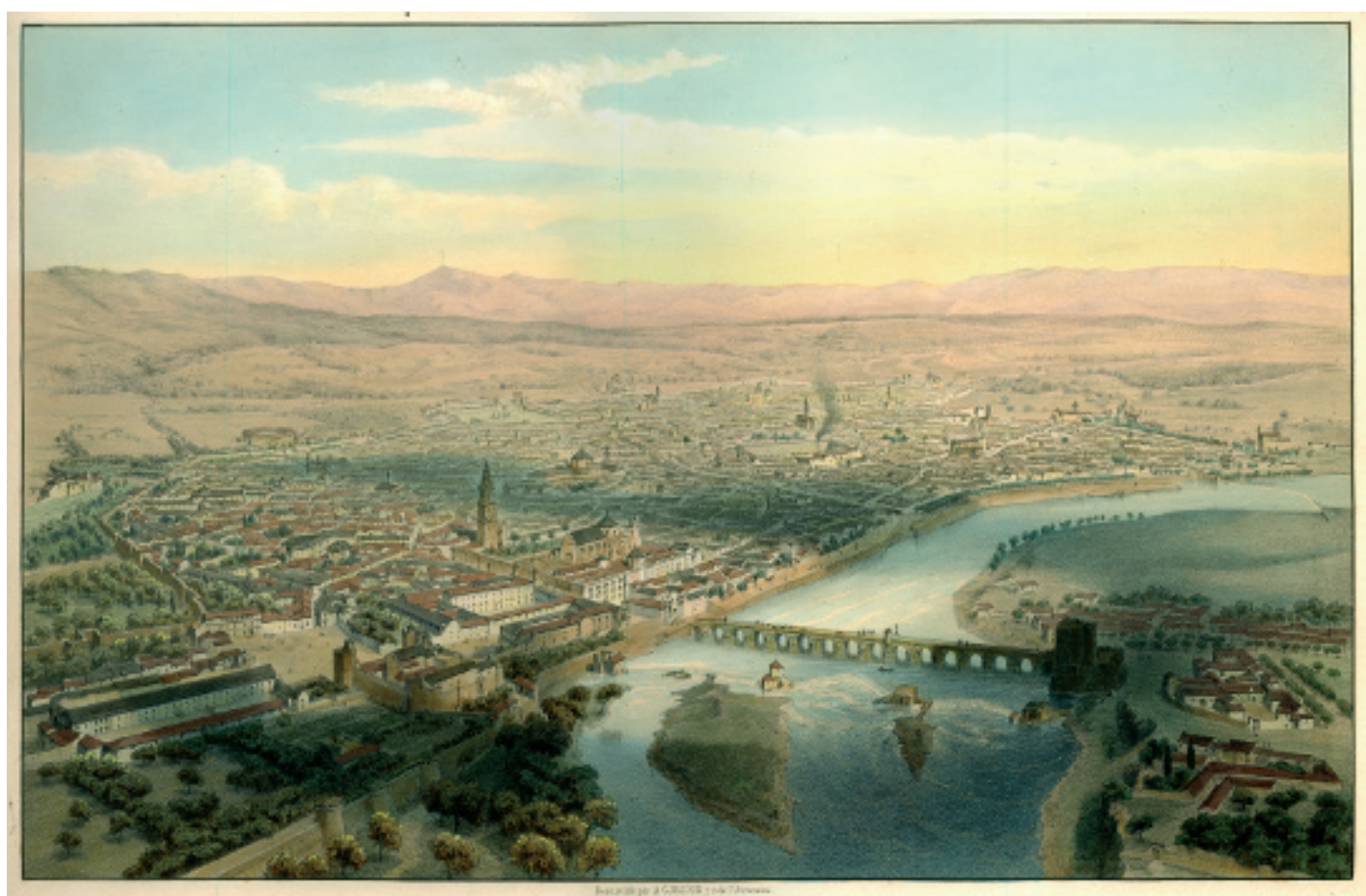

Fig. 8. Alfred Guesdon: Vista aérea de Córdoba [litografía coloreada], h. 1853.

se conserva hoy en la Gerencia Municipal de Urbanismo de Córdoba. Es un fiel reflejo de la ciudad del momento, con la salvedad del borde fluvial urbano y su muro de defensa ante las crecidas del Guadalquivir, representado en el plano, aunque apenas se había ejecutado ${ }^{29}$. Esta inexactitud se subsanó en un segundo plano coetáneo a la vista de Guesdon, el de Montis (1851). Está basado en el anterior pero introduce novedades, como el citado muro junto al río, ya construido en un amplio tramo entre el molino de Martos y la calle La Feria; o la apertura del paseo de San Martín en 1843 sobre los terrenos del desamortizado convento homónimo, al norte de la ciudad.

\section{La ciudad de Córdoba dibujada por Guesdon}

Seguidamente se analiza la vista de Guesdon, atendiendo a destacados aspectos que conformaban la imagen y estructura de la ciudad: su encuadre territorial y paisajístico, la fachada al río, la forma urbana (perímetro defensivo y caserío interior) y los principales hitos arquitectónicos. Ello nos permite recorrer hoy aquella Córdoba de mediados del XIX, heredera en gran medida de su etapa bajomedieval, en momentos previos a importantes transformaciones urbanas ${ }^{30}$.

29 Aprobado su proyecto en 1792, su construcción comenzaría en 1794, avanzando lentamente y con paralizaciones durante el siglo XIX (García Verdugo, 1992: 61-62). En 1833 David Roberts dibujó un tramo en una de sus vistas cercana al meandro; también aparece en la vista de Taylor (1825-32). Gámiz Gordo / García Ortega, 2015: 373-376.

30 Puchol Caballero, 1992: 19. También véase, Rey Carmona, 2010. 


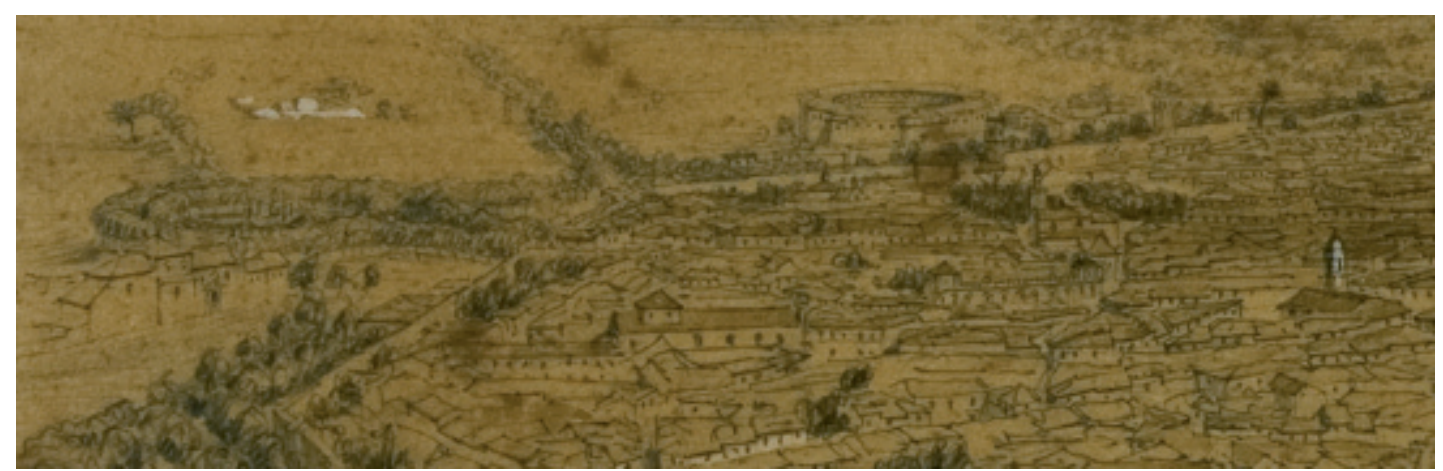

Fig. 9. Alfred Guesdon: Vista aérea de Córdoba [detalle del sector noroccidental, con la plaza de toros y el Paseo de la Victoria], 1853.

\section{El paisaje circundante}

La ciudad se enmarca en un atractivo entorno natural que Guesdon dibujó con fidelidad, pese a que en aquel momento no existía cartografía precisa sobre éste y lógicamente no pudo deducir el perfil montañoso del plano de Montis. A poniente, en primer plano, aparecen las arboledas de la Huerta del Rey, y más allá las del Paseo de la Victoria. Como fondo se aprecian las primeras estribaciones de Sierra Morena, precedidas por colinas y suaves accidentes topográficos, urbanizados o transformados en el siglo XX. El territorio contiguo al casco histórico, sustancialmente plano, estaría ocupado desde tiempos inmemoriales por instalaciones artesanales, que daban nombre a distintos arrabales (Ollerías, Tejares, Matadero...). Esta zona fue también ocupada por implantaciones religiosas que constituyeron un auténtico cinturón conventual, por entonces en estado de abandono. Se aprecian los antiguos monasterios de La Victoria al oeste, el de La Merced (ahora hospicio) y San Cayetano al norte, y los de San Juan de Dios y Madre de Dios, al este.

Dicho entorno empezó a transformarse con la exclaustración forzosa y desamortización de los conventos; y con la implantación de dos importantes elementos lúdicos: el Paseo de la Victoria, hacia el noroeste junto al convento del mismo nombre ${ }^{31}$, y el nuevo coso taurino, inaugurado en 1846. En 1859, a unos 300 metros al norte, aparecería el ferrocarril, transformando definitivamente este paisaje dibujado por Guesdon (fig. 9).

\section{La fachada urbana al río Guadalquivir}

Particularmente bellos y sugerentes resultan los primeros planos del dibujo, con la monumental fachada urbana al Guadalquivir, y sus arboledas, molinos, azudas... como lugar propicio para el esparcimiento e incluso para la pesca, según reflejan otras vistas históricas. En primer plano aparecen perfectamente definidas las cubiertas de la Mezquita-Catedral, no reflejadas en el plano de la ciudad de Montis. Entre otros aspectos se dibujan sus pequeños lucernarios, algunos hoy desaparecidos $^{32}$, que no podían percibirse desde la calle, ni desde la propia torre del templo.

También se aprecia el Alcázar de los Reyes Cristianos, antigua sede de la Inquisición y entonces cárcel (fig. 10). Sus formas son coherentes con otros dibujos de la época, y resultan in-

\footnotetext{
31 Dicho ajardinamiento ya aparece, aunque menos formalizado, en el plano de 1811.

32 Estos lucernarios aparecen también en algunas vistas del XIX de Roberts y Laborde, que corroboran su existencia. Gámiz Gordo / García Ortega, 2015: 381-386.
} 


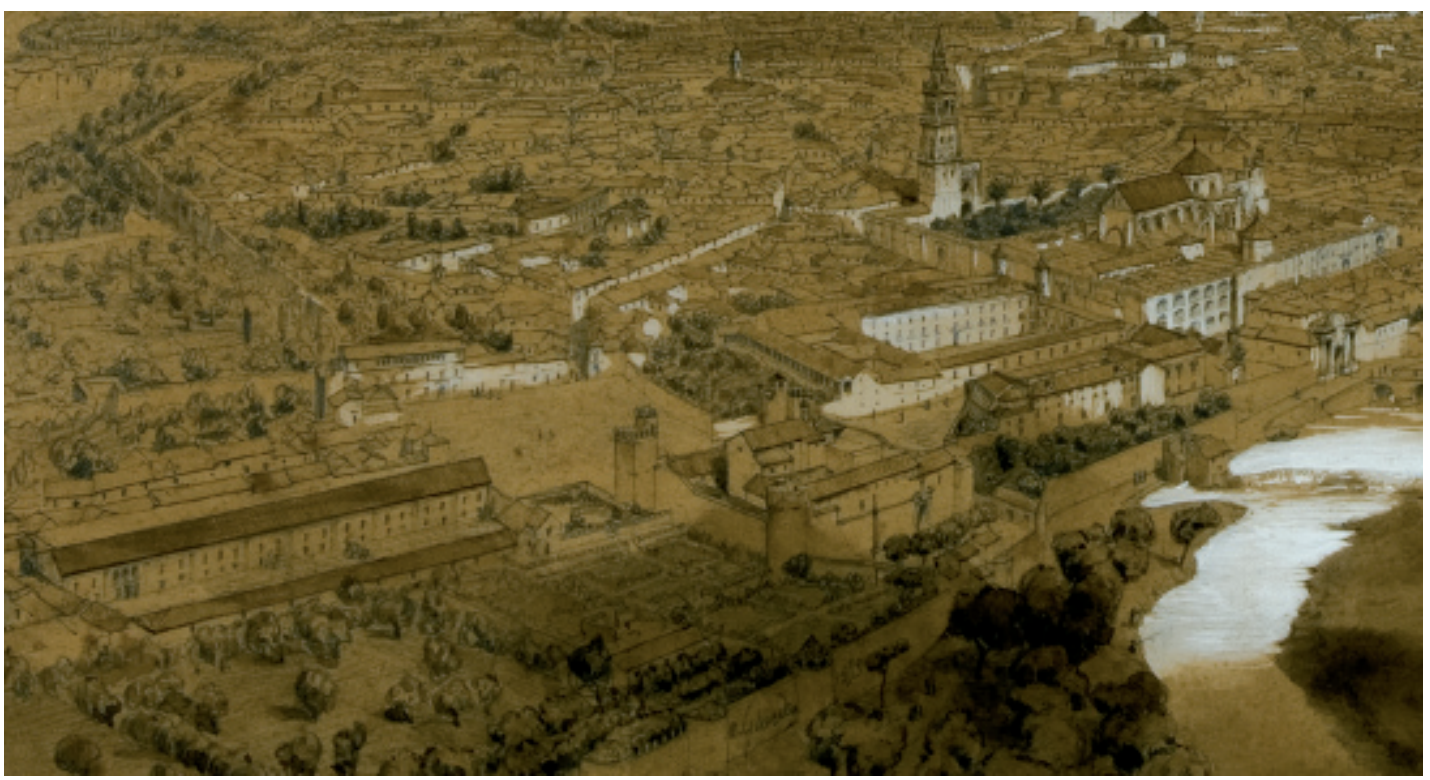

Fig. 10. Alfred Guesdon: Vista aérea de Córdoba [detalle primeros planos del sector suroccidental, con las Caballerizas Reales, Alcázar y Mezquita-Catedral], 1853.

cluso más precisas que las vistas de Roberts hacia 1833. En su interior destacaba una gran columna sobre pedestal situada junto a su fachada al río, que no se refleja en la cartografía urbana de la época, aunque está documentada en una de las primeras fotos del Alcázar, de Ferrier y Soulier $(1857)^{33}$. Dicha foto concuerda a la perfección con el dibujo de Guesdon ${ }^{34}$, corroborando detalles como el pequeño volumen de desembarco de la escalera que subía al lienzo norte del Alcázar, adosado a la torre de los Leones, y hoy desaparecido. Obviamente dicho volumen se omite en el plano de Montis, que sólo representa el contorno del edificio, al igual que el plano de 1811. Todo ello hace pensar en una visión desde un globo aerostático.

Por otra parte en la vista de Guesdon se constata que ya no existían las edificaciones auxiliares en "L" anexas a la torre suroeste del Alcázar, representadas en ambos planos urbanos. Su lugar lo ocupaba un jardín de crucero, que obviamente Guesdon no inventó. Estamos ante un evidente indicio de que el dibujante utilizaba información de primera mano, seguramente fotográfica.

La muralla que confinaba las huertas y jardines del Alcázar se prolongaba hasta enlazar con la Puerta del Puente. Entre dicho punto y la Cruz del Rastro, a levante, la cerca estaba ruinosa o camuflada entre el caserío; y hacia el molino de Martos, en el meandro, había resultado totalmente destruida al construirse las defensas del río, ocupando su lugar un nuevo paseo arbolado. El muro de contención de la vista es coincidente con el plano de Montis y con la documentación del Archivo Histórico Municipal.

Junto al frente monumental del Alcázar, Palacio Episcopal y Mezquita-Catedral, la fachada de la ciudad al río quedaba conformada por un caserío de menor escala que se extendía hasta el límite oriental, con el desaparecido convento de los Santos Mártires. También destaca la hoy casi desaparecida parroquia de San Nicolás de la Ajerquía, cuya cuidada representación volumétrica constituye un valioso testimonio gráfico de su configuración (fig. 11).

\footnotetext{
33 Gámiz Gordo / García Ortega, 2012: 17-18.

34 Se detecta un error de transcripción en la litografía, que representa la torre sureste, o de la Paloma, como circular, cuando en el dibujo se recoge adecuadamente como cuadrada.
} 


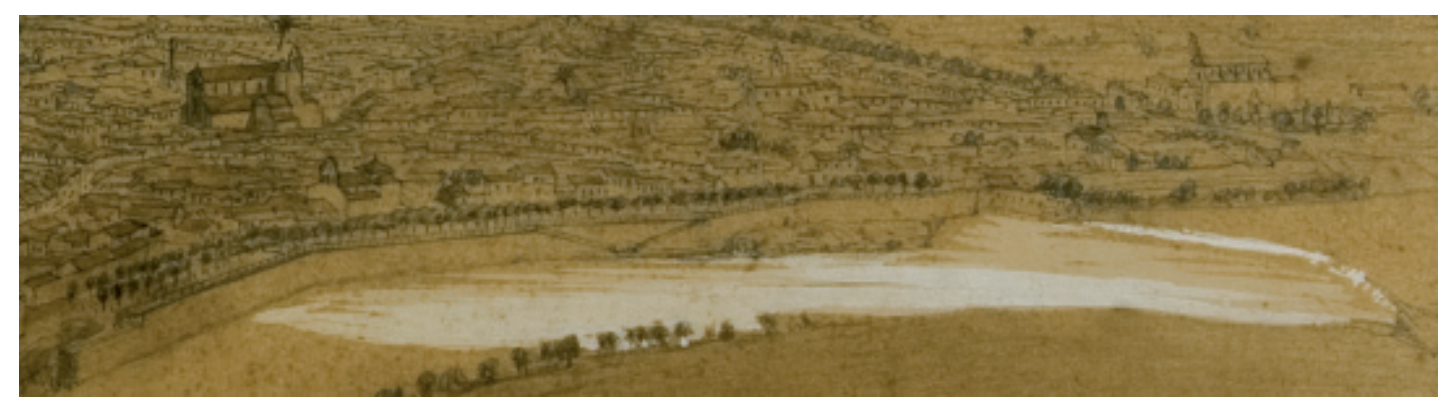

Fig. 11. Alfred Guesdon: Vista aérea de Córdoba [detalle de la fachada urbana al Guadalquivir, entre San Nicolás y el convento de los Mártires], 1853.

\section{La forma urbana}

El perímetro urbano se dibuja de forma fiel, concordando con el plano de Montis y otros documentos gráficos de la época. El trazado de la muralla puede seguirse en casi todo su perímetro, aunque apenas se aprecia en algunos tramos, como el de la actual Ronda del Marrubial, dibujado por Ford y Vivian, y perfectamente representado en el plano de Montis. Este dato resulta muy significativo, ya que si la perspectiva se hubiese dibujado a partir del citado plano, no se habría omitido dicho tramo de muralla.

En el frente del río se reconocen algunas puertas del recinto, como la del Puente, también dibujada por Roberts o Parcerisa, y la de Martos, junto al molino homónimo. En el lienzo oriental aparece la puerta Nueva, la de Baeza ${ }^{35}$, y la de Plasencia ${ }^{36}$; en el lienzo norte la del Colodro, la puerta de Osario ${ }^{37}$ y la del Rincón, ésta sólo intuida por la torre de igual nombre contigua ${ }^{38}$; y en el flanco oeste está la de Almodóvar, única que conserva hoy su conformación islámica. Se omiten la de Andújar, oculta tras el volumen de la parroquia de La Magdalena, la de la Misericordia (muy lejana en el lienzo norte) y la de Gallegos, aunque se representa el sector occidental de muralla en el que se integraba.

También destacan torres singulares, como la albarrana de la Malmuerta, unida a la misma por un arco, y la desaparecida de los Donceles, junto a la puerta de Andújar. Al otro lado del puente se dibuja la Calahorra, defendiendo su entrada, con una compleja configuración fruto de innumerables reformas. Tuvo incluso un recinto amurallado anejo, de origen almohade ${ }^{39}$, del que aún se aprecian restos en las vistas de Wyngaerde y del Civitates Orbis Terrarum, constatando Guesdon su total desaparición.

Todo este cinturón defensivo alojaba en su interior un complejo entramado urbano, un abigarrado caserío con pequeñas plazas o ensanches de calles. A la espera de las grandes reformas y aperturas de época isabelina, escaseaban los espacios públicos con tamaño y formalización significativos. Tan sólo destacaban el Campo Santo de los Mártires, al suroeste frente al Alcázar, o una de las más cualificadas plazas mayores andaluzas, la Corredera. Al norte, ya extramuros, se distingue el Campo de la Merced, denominado así por el convento que allí hubo. Y entre los espacios privados sólo destacan el inmenso patio de las Caballerizas Reales, al suroeste, el patio de carruajes del Palacio Episcopal, junto a la Mezquita-Catedral, y el Patio de los Naranjos de ésta.

\footnotetext{
35 Plano de 1762. Archivo Histórico Municipal, Córdoba (AHM), C-0766 legajo 036.

36 Plano de 1757. AHM, sección 08, C-0766, serie 04.

37 Plano de 1752. AHM, C-0766, legajo 023.

38 Plano inédito de 1759. AHM, C-0766, legajo 029.

39 Vaquerizo Gil, 2003: 213.
} 
El resto de grandes vacíos urbanos eran interiores de manzana o antiguos huertos conventuales en desuso tras la desamortización. Algunos, como el huerto del dominico de San Pablo, apenas se vislumbran; otros, como los que rodean a San Hipólito son más evidentes, apreciándose menor densidad del caserío en este sector noroeste de la Villa.

Para dibujar todo ello con precisión, y en especial los interiores de manzanas, resulta muy improbable que se acometiese una toma de datos in situ, pues resultaría muy lenta y laboriosa. Más bien se usaría una foto aérea, general o parcial. Sólo así se explica la representación del caserío acorde con el parcelario, así como sus cubiertas, que obviamente no se reflejan en el plano de Montis. También sorprende el detalle con el que se dibujan innumerables fachadas y patios interiores privados. Por otra parte resulta muy significativo que algunas manzanas que Montis representa como edificadas en el sector norte, posiblemente copiadas del plano de Karwinski (1811), están sin construir en la vista de Guesdon. Esta otra enmienda a la cartografía del momento sugiere, de nuevo, el uso de fotografías aéreas como fuente primaria del dibujo.

Dichas discrepancias, junto a todo lo expuesto, evidencian que el plano de Montis no bastaba por sí solo para confeccionar la vista aérea, aunque pudo ser una herramienta muy útil para interpretar la superposición visual del caserío, y representar fielmente la estructura urbana, calles y plazas, incluso en zonas más alejadas del punto de vista. Así, la calle Feria, que divide los dos grandes sectores urbanos de la Villa (occidental) y Ajerquía (oriental), es reconocible desde su arranque junto al río, en la Cruz del Rastro, hasta la puerta del Rincón, al norte; y también se identifican los importantes viarios que de este a oeste recorrían la urbe, enlazando las puertas de la muralla.

\section{Hitos del casco histórico}

Desde la conquista cristiana en 1236 la ciudad quedó sectorizada en ámbitos civiles o collaciones, coincidentes con las circunscripciones parroquiales. Éstas constituían una red de nodos urbanos que conformaron la imagen de la ciudad durante siglos, según ilustra el singular dibujo de la colección Vázquez Venegas $(1752)^{40}$.

En la vista de Guesdon se representan con esmero los templos parroquiales, sobresaliendo entre el caserío. Aunque su conformación arquitectónica es en general correcta, resulta evidente cierta voluntad de estilizar sus volúmenes para acentuar su carácter de hito, incluso omitiéndose a veces las capillas funerarias adosadas, como ocurre en Santiago, Santa Marina o San Lorenzo. Dicha estilización resulta evidente en parroquias medievales de la Ajerquía, como Santa Marina, San Lorenzo, San Andrés, La Magdalena, San Pedro y Santiago, o la conventual de San Agustín; y también en iglesias posteriores como la de los Padres de Gracia, o la imponente cúpula neoclásica de Santa Victoria, en el entorno de la Villa.

En dicho sector se reconocen otras iglesias con una volumetría mucho más discreta. Entre las parroquiales estarían las de San Juan, San Miguel o San Nicolás de la Villa, y las conventuales de los Trinitarios, de la Compañía de Jesús, o San Hipólito, en la que pese a su lejanía en la zona noroeste se detallan fielmente cubiertas y ventanales, ocultos desde la calle y sólo visibles desde considerable altura. También se aprecia Santa Clara, antigua mezquita cristianizada tras la conquista castellana, cuya cubierta se detalla muy bien hasta en sus más pequeños pormenores ${ }^{41}$, algo que en la práctica sólo es posible dibujar a partir de una precisa toma fotográfica. Todo ello apunta, de nuevo, a una necesaria ascensión en globo aerostático.

Como contrapunto, apenas se reconocen edificios civiles y casas palaciegas. También aparece una singular chimenea humeante junto a la plaza de la Corredera, posiblemente de la fábrica de sombreros que desde principios de siglo se alojó en los antiguos edificios del Pósito y de la

\footnotetext{
40 García Ortega / Gámiz Gordo, 2010.

${ }^{41}$ Se dibuja el pequeño "cuchillo" de su cubierta generado al cubrirse el patio, que obviamente no aparece en la planimetría urbana.
} 


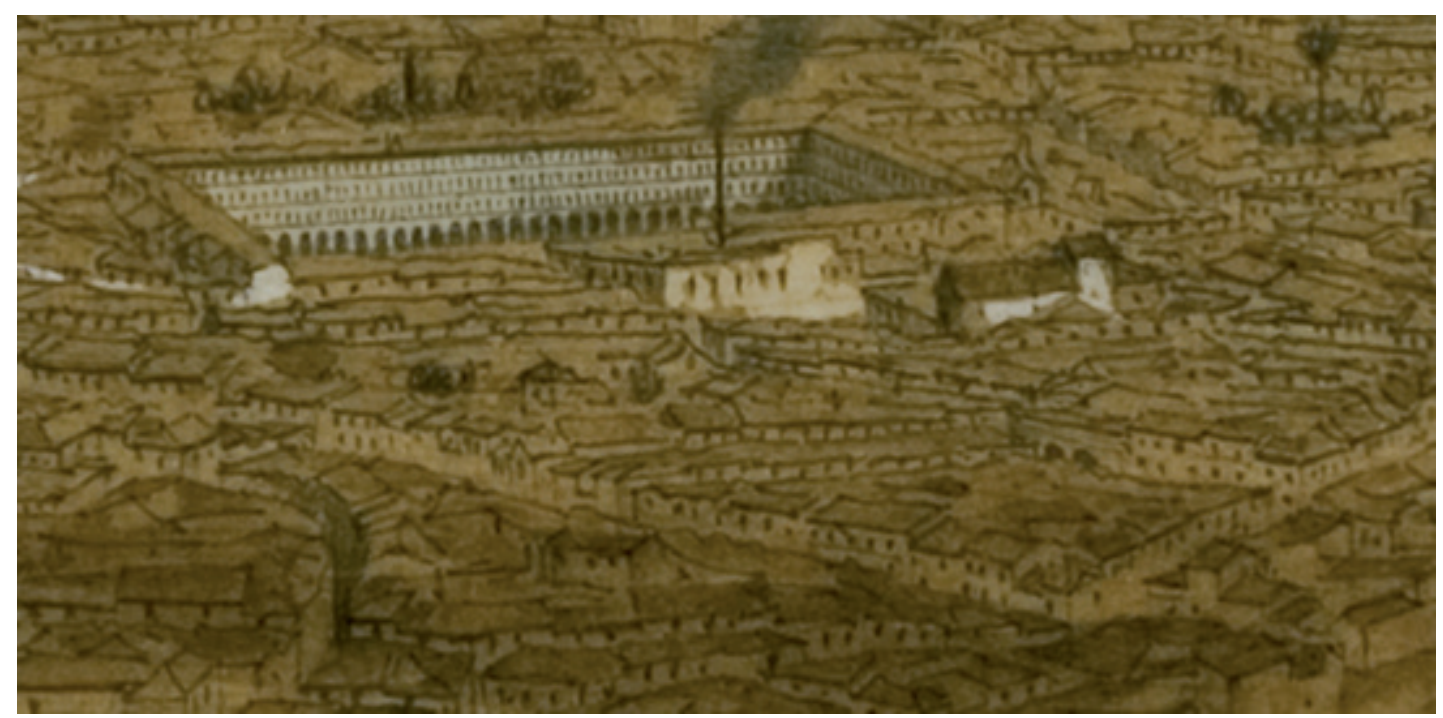

Fig. 12. Alfred Guesdon: Vista aérea de Córdoba [detalle de la zona central de la Ajerquía, con el templo de San Francisco junto a la plaza de la Corredera], 1853.

Casa del Corregidor. Otros edificios, más modestos, no se distinguirían desde cierta altura y lejanía, y menos aún los detalles tan minuciosos y precisos representados. Ello hace pensar que Guesdon pudo usar fotos parciales más cercanas, y también apoyarse en el plano de Montis, que rotula y sitúa muchos lugares y edificios. Así, cabe pensar en un dibujo ejecutado en dos tiempos: primero un encaje general apoyado en imágenes imperfectas tomadas desde un globo, con los incipientes adelantos fotográficos, y una posterior incorporación de elementos singulares, cuyos detalles conocía gracias a otros dibujos, planos o fotos parciales.

Dicho proceso dio lugar a dos importantes errores al representar los grandes edificios conventuales de San Pablo y San Pedro el Real (conocido como San Francisco). El primero, dominico y ubicado en la parte central de la ciudad, aparece dibujado sólo parcialmente, interrumpiéndose su larga nave. Ello denota las imperfecciones de la técnica usada para la obtención general de la vista, que no permitió interpretar su volumen conventual. Más significativo es el error en el otro templo, integrado en un vasto complejo franciscano cuya iglesia y claustro se dibujan más pequeños y desplazados doscientos metros al noreste de su verdadera ubicación; así, aparecen en la plaza de las Cañas, junto a la Corredera, donde realmente estaba la capilla de la Piedad. Este error nunca se hubiera producido al transcribir una fotografía única o al obtener la perspectiva a partir de un plano como el de Montis, que lo ubica perfectamente (fig. 12). Curiosamente en esta zona se representa la sombra arrojada de una nube, que quizás dificultó la primitiva toma fotográfica o le hizo perder nitidez.

Por último, resulta llamativa la cantidad de elementos menores que animan la vista, y especialmente el arbolado, a veces palmeras, haciéndola muy atractiva. Éstas no serían inventadas, ya que diversas fuentes documentales, escritas o graficas, dan testimonio de su existencia, dándole a la ciudad cierto aire oriental que el artista supo captar. Concretamente las palmeras ubicadas junto al lienzo noreste de la muralla (actual Ronda del Marrubial) son recogidas en el mismo lugar en otras vistas de la época, como las de Ford en 1833 o Vivian hacia 1834, demostrando la escrupulosa veracidad de la imagen estudiada. También en esta zona se dibujan unos postes, detallados en dichas vistas, previas a la aparición de la fotografía. Todo ello indica de nuevo que un levantamiento planimétrico era a todas luces insuficiente para confeccionar la detallada y fiel vista aérea de Guesdon, ya que los planos de la ciudad existentes no reflejaban estos elementos menores. 


\section{Conclusiones}

El análisis de la vista aérea de Córdoba evidencia que es demasiado perfecta como para haberse realizado sin el auxilio de los avances técnicos de la época. Seguramente Guesdon debió de manejar el plano de la ciudad de Montis de 1851, aunque por sí sólo éste no sería suficiente al carecer de la delimitación parcelaria u otros muchos detalles reflejados en la vista, como el entorno territorial, fachadas interiores, vacíos urbanos, arbolado o cubiertas. Éstas, además, a veces se representan con pormenores de enorme precisión, como ocurre en el convento de Santa Clara. Por ello debe descartarse un simple proceso de puesta en perspectiva a partir del plano, que hubiera contado con las dificultades de la estimación de las diferentes alturas de los edificios, y cómo se tapan unos volúmenes a otros, aspectos muy coherentes y realistas en la composición analizada. Además en este caso, no se hubieran omitido aspectos tan expresos en el plano como algunos lienzos amurallados, o se hubieran asumido errores del mismo, como los jardines del Alcázar y sus construcciones auxiliares.

Por otro lado, la existencia de ciertos errores en el dibujo parece a primera vista incompatible con el uso exclusivo de la fotografía, una técnica aún incipiente e imperfecta. Sin embargo, dado el adecuado encaje en perspectiva cónica de la ciudad, debe considerarse el empleo de fotografías tomadas desde un globo como punto de partida en la construcción del dibujo de la urbe y su entorno, cuyo entramado pudo interpretarse con la ayuda del plano de Montis. En este sentido resulta sorprendente la correcta y detallada estructuración urbana de la vista aérea, en la que virtualmente es posible recorrer la ciudad calle a calle.

En esta composición general el autor encuadró los principales hitos arquitectónicos, en la ubicación que pudo deducir de plano y foto, proceso en el que cometió algunos errores, incomprensibles de otra manera. Para ello debió de contar con fotos o dibujos parciales, útiles para distinguir los detalles de muchos edificios o lugares, imposibles de percibir desde los más elevados miradores de la ciudad. Este dibujo, fruto pues de una técnica mixta, sería la base para el grabado, que incluye leves diferencias achacables a descuidos o a dificultades de interpretación del dibujo original.

En definitiva, la vista analizada de Alfred Guesdon evidencia una clara voluntad de representar fielmente la realidad urbana y territorial de Córdoba. Para ello aunó los avances técnicos del momento con la tradicional disciplina del dibujo, con un elevadísimo nivel de virtuosismo y sensibilidad. De este modo se obtuvo una de las más bellas vistas en la historia gráfica de Córdoba, un verdadero símbolo de su identidad urbana, que más allá de su mera descripción captó la esencia de aquella ciudad de mediados del siglo XIX.

\section{BIBLIOGRAFÍA}

Benet, Juan (1983): Ingeniería en la época romántica. Las obras públicas en España alrededor de 1860. Madrid: M.O.P.U. Besse, Jean-Marc (2013): "European cities from a Bird's-eye view. The case of Alfred Guesdon”. En: Seeing from above. The aerial view in visual culture, pp. 66-82. Londres: I. B. Tauris.

Bullough Ainscough, Rachel (2015): "Charles Clifford. Globos y caballos". En: Revista Internacional de la Imagen, 2 , pp. 129-137.

Cosano Moyano, Francisco (1999): Iconografia de Córdoba. Siglos XIII-XIX. Córdoba: Cajasur.

Delarue, François (1858): Catalogue de fonds et d'assortiment de François Delarue, éditeur d'estampes, commissionnarie, imprimeur. París.

Fontanella, Lee (1999): Clifford en España. Un fotógrafo en la Corte de Isabel II. Madrid: El Viso.

Gámiz Gordo, Antonio (2004): "Paisajes urbanos vistos desde globo: dibujos de Guesdon sobre fotos de Clifford hacia 1853-55”. En: EGA Revista de Expresión Gráfica Arquitectónica, 9, Valencia, pp. 110-117.

Gámiz Gordo, Antonio / García Ortega, Antonio Jesús (2012): "Vistas del Alcázar de los Reyes Cristianos de Córdoba hasta mediados del siglo XIX". En: Reales Sitios. Revista de Patrimonio Nacional 193, pp. 4-19.

Gámiz Gordo, Antonio / García Ortega, Antonio Jesús (2015): "David Roberts en Córdoba. Vistas de Paisaje y Arquitectura hacia 1833". En: Archivo Español de Arte, 352, pp. 367-386.

García Espuche, Albert (1994): Ciudades del globo al satélite. Barcelona: Electa.

García Ortega, Antonio Jesús / Gámiz Gordo, Antonio (2010): "La ciudad de Córdoba en su primer plano: un dibujo esquemático de 1752”. En: Archivo Español de Arte, 329, pp. 23-40. 
García Verdugo, Francisco (1992): Córdoba, burguesía y urbanismo. Córdoba: Gerencia de Urbanismo de Córdoba.

Garófano Sánchez, Rafael (2014): "Una imagen demasiado perfecta”. En: Diario de Cádiz, 21-7-2014.

Granado Castro, Gabriel (2012): El Cádiz de la Ilustración. Técnica cartográfica y sociedad a través del Bajorrelieve de Alfonso Ximénez. Sevilla: tesis doctoral inédita, Universidad de Sevilla.

Granado Castro, Gabriel / Martín Pastor, Andrés (2016): "The 3d Model-Map of Cadiz (1779): A Unique Project of Cartography in Modern Spain”. En: The Cartographic Journal, 53, 3, pp. 268-281.

Lleó Cañal, Vicente (1986): "Estampas andaluzas". En: 1. ${ }^{a}$ Bienal iberoamericana de arte seriado. Grabados históricos de tema andaluz. Sevilla: Consejería de Cultura de la Junta de Andalucía.

Marjonneau, Charles (junio 1876): “M. Alfred Guesdon, Architecte, dessineateur et lithographe”. En: Revue de Bretagne et de vendee, pp. 485-491.

Kurtz, Gerardo F. (1997): “Charles Clifford, aeronauta y fotógrafo, Madrid 1850-1852”. En: Charles Clifford, fotógrafo de la España de Isabel II. Madrid: El Viso, pp. 41-70.

Pardo González, Juan Carlos (1995): “Alfred Guesdon: litografías sobre Gibraltar”, Almoraima: revista de estudios campogibraltareños, 13, pp. 391-395.

Porres Martín-Cleto, Julio / Cerro Malagón, Rafael Juan del / Isabel Sánchez, José Luis (1991): Toledo visto por el litógrafo Alfred Guesdon. Toledo: Instituto de Estudios Toledanos.

Pérez Gallardo, Helena (2015): Fotografía y Arquitectura en el siglo XIX. Historia y representación monumental. Madrid: Cátedra.

Puchol Caballero, María Dolores (1992): Urbanismo del Renacimiento en la ciudad de Córdoba. Córdoba: Diputación Provincial de Córdoba.

Quirós Linares, Francisco (1991): Las ciudades españolas en el s. XIX. Vistas de ciudades españolas de Alfred Guesdon. Planos de Francisco Coello. Valladolid: Ámbito Ediciones.

Reps, John W. (1984): Views and Viewmakers of Urban America: Lithographs of Towns and Cities in the United States and Canada, Notes on the Artists and Publishers, and a Union Catalog of Their Work, 1825-1925. Missouri: University of Missouri.

Reps, John W. (1998): Bird's Eye Views - Historic Lithographs of North American Cities. Nueva York: Princeton Architectural Press.

Rey Carmona, María (2010): Córdoba en el romanticismo: de la guerra de la independencia a la revolución gloriosa. Córdoba: Universidad de Córdoba y Ayuntamiento de Córdoba.

Rius, Nuria F. (2012): Barcelona fotografiada des de l'aire: Alfred Guesdon. Antonio Castelucho i Antoni Esplugas (c. 1850, 1882, 1888), https://nuriafrius.com/author/nuriarius/ [10-09-2012].

Rodríguez Ruiz, Delfín (2015): "Fotografía y Arquitectura. Ideas e historias de un encuentro anunciado". En: Mirar la Arquitectura. Fotografía monumental en el siglo XIX. Madrid: Biblioteca Nacional, pp. 15-31.

Stroffolino, Daniela (2012): L'Europa “a volo d'uccelo”. Dal cinqueccento ad Alfred Guesdon. Nápoles: Edizioni Scientifiche Italianne.

Torrella, Rafel / García Felguera, Maria de los Santos / Martí Baiget, Jep / Ferrer Godoy, Joan (2014): El daguerrotipo. El inicio de la fotografía, Arxiu Fotogràfic de Barcelona-Institut de Cultura-Ajuntament de Barcelona.

Vaquerizo Gil, Desiderio (dir.) (2003): Guía Arqueológica de Córdoba. Córdoba: Plurabelle.

Fecha de recepción: 10-XI-2016

Fecha de aceptación: 14-II-2017 